\title{
Engineering Escherichia coli to overproduce aromatic amino acids and derived compounds
}

\author{
Alberto Rodriguez, Juan A Martínez, Noemí Flores, Adelfo Escalante, Guillermo Gosset and Francisco Bolivar ${ }^{*}$
}

\begin{abstract}
The production of aromatic amino acids using fermentation processes with recombinant microorganisms can be an advantageous approach to reach their global demands. In addition, a large array of compounds with alimentary and pharmaceutical applications can potentially be synthesized from intermediates of this metabolic pathway. However, contrary to other amino acids and primary metabolites, the artificial channelling of building blocks from central metabolism towards the aromatic amino acid pathway is complicated to achieve in an efficient manner. The length and complex regulation of this pathway have progressively called for the employment of more integral approaches, promoting the merge of complementary tools and techniques in order to surpass metabolic and regulatory bottlenecks. As a result, relevant insights on the subject have been obtained during the last years, especially with genetically modified strains of Escherichia coli. By combining metabolic engineering strategies with developments in synthetic biology, systems biology and bioprocess engineering, notable advances were achieved regarding the generation, characterization and optimization of $E$. coli strains for the overproduction of aromatic amino acids, some of their precursors and related compounds. In this paper we review and compare recent successful reports dealing with the modification of metabolic traits to attain these objectives.
\end{abstract}

Keywords: Aromatic compounds, Escherichia coli, Metabolic engineering, Systems biotechnology, Synthetic biology, Shikimate pathway, Phenylalanine, Tyrosine, Tryptophan

\section{Introduction}

The aromatic amino acids (AAA), L-tryptophan (L-TRP), L-phenylalanine (L-PHE) and L-tyrosine (L-TYR), are the final products of the aromatic biosynthetic pathway comprising the shikimate (SHK) pathway, which connects central carbon metabolism (CCM) with the biosynthesis of chorismate (CHA), the last common precursor in the terminal branches for AAA biosynthesis (Figure 1) $[1,2]$. These pathways are present in bacteria and in several eukaryotic organisms such as ascomycetes fungi, apicomplexans, and plants [3,4]. The AAA are essential components in the diet of higher animals and humans, hence they are used as dietary supplements (e.g. diet of swine and poultry consisting of grains of corn and soybean is low in L-TRP) and key precursors of industrial and pharmaceutical compounds (e.g. L-PHE is the key ingredient in the synthesis of the artificial sweetener

\footnotetext{
* Correspondence: bolivar@ibt.unam.mx

Departamento de Ingeniería Celular y Biocatálisis, Instituto de Biotecnología, Universidad Nacional Autónoma de México (UNAM), Avenida Universidad 2001, Col. Chamilpa, Cuernavaca, Morelos 62210, México
}

aspartame, whereas L-TYR is an essential dietary component for phenylketonuria patients as the starter material for L-DOPA or melanin production) [5]. The annual worldwide production of amino acids is estimated to be above 4.5 million tons/year, with a market growth for most amino acids of $\sim 10 \%$ and higher [6,7]. Among the aromatic amino acids, L-TRP has a market size of more than 14,000 tons/year [8] and the production of L-PHE exceeds 30,000 tons/year [9].

It is well established that the production of high-valued commodities can be performed cost-efficiently by the rational design, modification and cultivation of a recombinant microorganism. In particular, the development of efficient microbial processes for accumulation of compounds derived from the AAA biosynthetic pathway has not been an easy task for metabolic and bioprocess engineers. For more than 20 years, considerable efforts have been directed towards characterizing and purposely overriding the naturally tight metabolic regulation of this pathway. These continued efforts have relied on knowledge obtained from pioneer works on the biosynthesis of aromatic compounds by the 


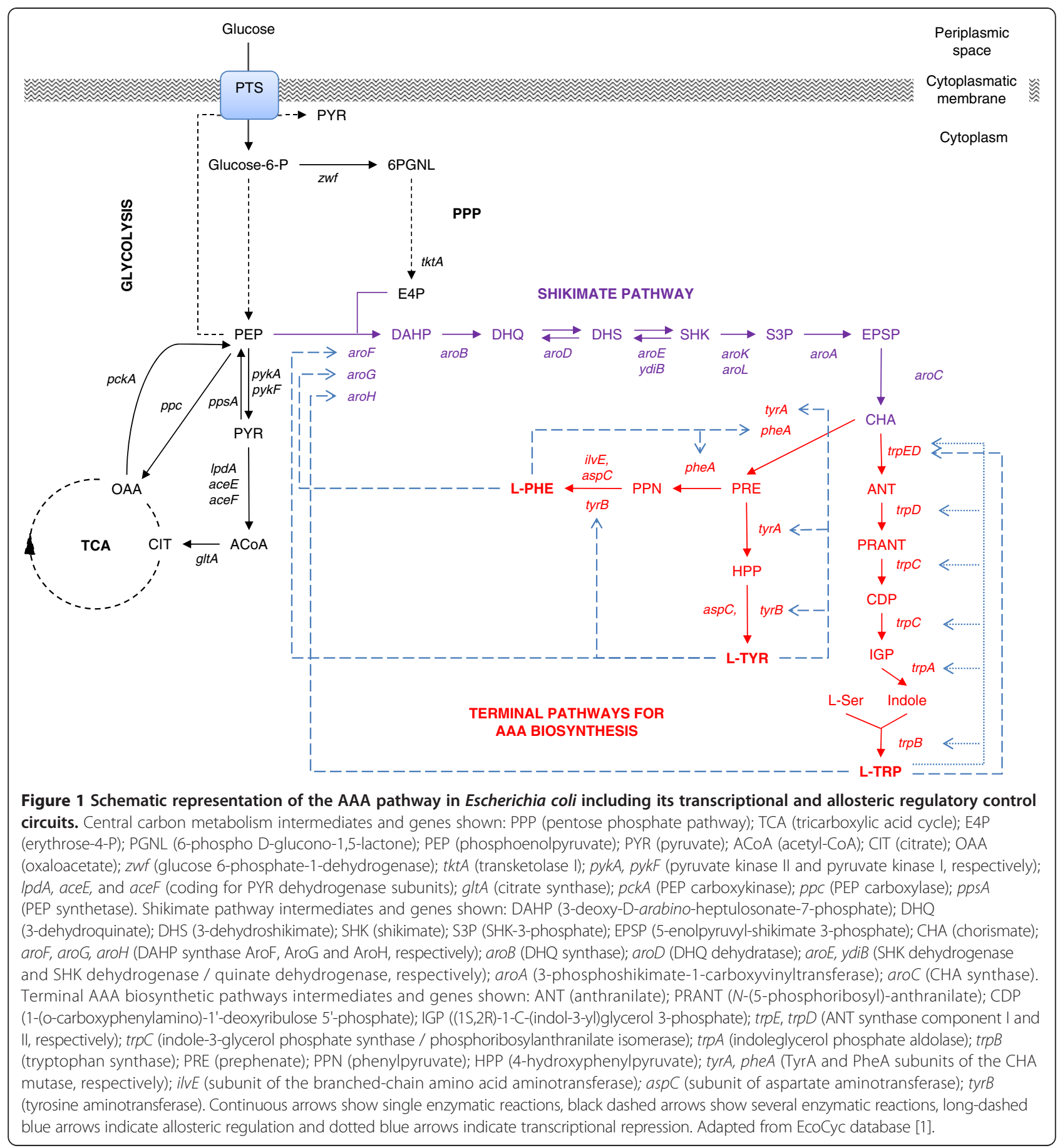

groups of B.D. Davis, F. Gibson, C. Yanofsky, A.J. Pittard, K.M. Herrmann and J.W. Frost, among others, whose contributions have been comprehensively reviewed in the past [2,10-12].

Recently, the availability of omics-scale data has allowed significant advances in metabolic reconstruction and modeling, resulting in better strain development [13]. Likewise, the increased use of combinatorial and evolutionary approaches, fueled by a rapid expansion of synthetic molecular tools, opened the possibility for testing novel and large combinations of gene expression systems and genetic backgrounds [14,15]. Additionally, efforts concerning the optimization of fermentation conditions have succeeded in scaling-up many AAA production processes, while simultaneously providing important feedback on the physiological behavior of engineered strains [16,17]. However, the availability of operational tools and techniques, as well as the amount of physiological and molecular information, 
are unevenly distributed among the microorganisms currently used for the production of AAA. These circumstances have contributed to positioning E. coli as the organism with most reported success cases and has resulted in a wide array of well-characterized production strains $[18,19]$.

In this paper we review some notable advances in the generation, characterization and optimization of $E$. coli strains for the overproduction of AAA, some of their important precursors and related compounds. Although these studies were classified in accordance to the main schemes employed for each case, the constant expansion and complementarity of such approaches has encouraged scientists to apply a systems-based perspective $[20,21]$. Therefore, recent and representative works on the subject using different strategies were selected and discussed.

\section{Engineering of the CCM: glucose transport, glycolytic, gluconeogenic, and pentose phosphate pathways}

Successful metabolic engineering efforts for the generation of $E$. coli strains that can overproduce AAA include: (i) increasing the availability of the direct precursors phosphoenolpyruvate (PEP) and erythrose-4-phosphate (E4P); (ii) enhancement of the first enzymatic reaction in the SHK pathway to yield 3-deoxy-D-arabino-heptulosonate-7phosphate (DAHP); (iii) improving the carbon flow through the biosynthetic pathway of interest by removal of transcriptional and allosteric regulation; (iv) identifying and relieving rate-limiting enzymatic reactions; (v) preventing loss of carbon flow towards competing pathways; (vi) enhancement of product export; and (vii) prevention of product degradation or re-internalization.

Regarding PEP metabolism, E. coli uses the phosphotransferase system (PTS) as the main system for the translocation and phosphorylation of glucose from the periplasmic space to the cytoplasmic environment, consuming one PEP molecule which is converted to pyruvate (PYR) [22,23]. This reaction yields one molecule of glucose-6-phosphate which is catabolized by the glycolytic pathway, resulting in two PEP molecules (Figure 1). PEP is a precursor feeding several biosynthetic pathways and also participates in ATP generation, either by substrate-level phosphorylation of ADP or indirectly as an acetyl coenzyme-A (ACoA) precursor. When E. coli grows in mineral broth containing glucose as the sole carbon source the PTS consumes $50 \%$ of the available PEP, whereas the reactions catalyzed by other enzymes such as PEP carboxylase, PYR kinases, UDP-N-acetylglucosamine enolpyruvyl transferase, and DAHP synthases (DAHPS), consume approximately $16 \%, 15 \%, 16 \%$, and $3 \%$ of remaining PEP, respectively $[23,24]$. Therefore, PEP can be converted to PYR by PTS and PYR kinases I and II (coded by $p y k F$ and $p y k A$ respectively), and PYR is converted to ACoA by the PYR dehydrogenase multienzyme complex (coded by aceE, aceF and $l p d$ ), a reaction connecting the glycolytic pathway with the tricarboxylic acid cycle (TCA) [1]. Moreover, PEP and PYR are key intermediates of the CCM as they are substrate of at least six enzymes which determine the metabolic fate of these intermediates (biosynthetic/catabolic pathways and glycolytic/gluconeogenic capabilities of the cell): DAHPS isoenzymes (AroF, AroG, and AroH coded by aroF, aroG and $\operatorname{aroH}$, respectively) [3,11]; PYR kinases I and II; PEP synthetase (PpsA coded by ppsA); PEP carboxylase (Ppc, coded by $p p c$ ); and PEP carboxykinase (PckA coded by $p c k A$ ) [25] (Figure 1).

Detailed knowledge of these nodes permitted the development of strategies that allowed higher PEP availability for the biosynthesis of aromatic compounds, including the replacement of glucose transport and phosphorylation capabilities of the PTS by alternative enzymes such as the glucose facilitator and glucokinase from Zymomonas mobilis (coded by $g l f$ and $g l k$, respectively) [26-28], the galactose permease and glucokinase from E. coli (coded by galP and $g l k$, respectively) [29,30], or the use of an adaptive evolution process to select $\mathrm{PTS}^{-}$derivatives growing at high specific growth rates $(\mu)$ on glucose [31,32]. Additionally, high PEP availability has been achieved by modulation of the carbon flux from PEP to the TCA caused by the inactivation of one or both of the PYR kinases [33,34], as well as improving the recycling of PYR to PEP by a plasmid-encoded copy of PEP synthetase [35-37]. The overexpression of $p c k A$, in combination with an enhanced carbon flow through the glyoxylate shunt, has also been proposed as a strategy to increase the yield of aromatic compounds [38,39]. An alternative approach to increase PEP is the attenuation of CsrA, a regulatory protein of carbohydrate metabolism, either by direct gene knockout or by increasing the expression of its negative regulatory RNA, coded by $\operatorname{csr} B[40,41]$.

On the other hand, E4P is a metabolite that participates in reversible reactions present in the non-oxidative branch of the pentose phosphate pathway (PPP), as well as a substrate in irreversible reactions that lead to the production of aromatic amino acids or vitamin $\mathrm{B}_{6}[42]$. E4P can also be directly produced from sedoheptulose1,7-bisphosphate in a reaction that is probably favored when the intracellular levels of sedoheptulose-7-phosphate are high [43]. Metabolic engineering reports have shown that a considerable increase in availability of E4P (inferred by the increased production of aromatic compounds and pathway intermediates, such as DAHP) can be achieved by overexpression of genes coding for a transketolase $(t k t A)[35,44-46]$ or a transaldolase $(\operatorname{talB})[26,47]$. Additional attempts to increase the carbon flow towards the PPP for enhanced production of aromatic compounds include the use of mutants lacking the enzyme phosphoglucose isomerase $[48,49]$, the overexpression of enzyme 
glucose-6-phosphate dehydrogenase $[41,50]$, or the use of multiple carbon sources, mainly hexoses, pentoses and glycerol [51-54]. After an adequate supply of precursors has been established, it is essential to commit this carbon towards the SHK pathway and to remove control points and limiting steps to increase the production of target compounds.

\section{Deregulation of the AAA pathway: identifying and relieving rate-limiting steps}

In E. coli, the DAHPS isoenzymes AroG, AroF and AroH contribute to the total DAHPS activity and are subjected to allosteric control by L-PHE, L-TYR and L-TRP, respectively (Figure 1). AroG contributes about $80 \%$ of the overall DAHPS activity, AroF about $15 \%$, and the remaining activity corresponds to AroH DAHPS [3,11]. Both the AroG and AroF isoenzymes are completely inhibited by about $0.1 \mathrm{mM}$ of the corresponding amino acids, but AroH is only partially inhibited by L-TRP. Apparent inability of L-TRP to totally inhibit this isoenzyme is proposed to be a mechanism to ensure a sufficient supply of $\mathrm{CHA}$ for the biosynthesis of other aromatic compounds when AAA are present in excess in the growth medium [3]. Specific amino acid residues involved in the allosteric sites have been identified by structural analysis of feedbackinsensitive mutant enzymes, resulting in the targeted generation of the feedback resistant (fbr) variants AroG $^{\mathrm{fbr}}$ and $\operatorname{AroF}^{\mathrm{fbr}}[28,31,55]$. Additionally to allosteric control of DAHPS isoenzymes, their transcriptional expression can be controlled by the tyr- and trp- repressors complexed with the AAA $[3,11]$.

Consequently, amplification and deregulation of DAHPS activity is an essential strategy to overproduce aromatic compounds and its precursor SHK. Introduction of plasmid-encoded copies of $\operatorname{aro} F^{\mathrm{fbr}}$ and $\operatorname{aro} G^{\mathrm{fbr}}$ combined with additional plasmid-cloned gene $t k t A$, or their chromosomal integrations in gene clusters, have resulted in increased carbon flow from the CCM to the SHK pathway for the production of L-PHE $[11,55,56]$, L-TYR $[5,57,58]$ and L-TRP [59-61]. Positive results were also obtained with the insertion of an aro $G^{\text {fbr }}$ gene into the chromosome of an L-PHE producing strain while being controlled by a promoter that is active during late cultivation stages, in order to counteract the fall of DAHPS activity in stationary phase [62].

Further increases in carbon flux through the SHK pathway have been attained by the removal of transcriptional and allosteric control points and by relieving limiting enzymatic reactions $[2,11,19,23]$. The reactions catalyzed by DHQ synthase (encoded by aroB) and SHK kinase isoenzymes I and II (encoded by aroK and aroL, respectively) are considered as rate-limiting [63-65]. In addition, the reaction catalyzed by the enzyme quinate/shikimate dehydrogenase (coded by $y d i B$ ) was also reported as limiting in the development of L-TYR production strains [58]. Either the overexpression of some of these genes by plasmid-cloned copies $[28,66]$, their co-expression in a modular operon under control of diverse promoters $[50,58,67]$, or their expression by chromosomal integration of additional gene copies and promoter engineering by chromosomal evolution [68], have relieved to a great extent these rate-limiting steps typically encountered during the development of SHK and AAA overproducing strains (Table 1). To date, genetically modified E. coli strains can overproduce SHK from glucose with yields in the range of 0.08 to $0.42 \mathrm{~mol} \mathrm{SHK} / \mathrm{mol}$ glucose under diverse culture conditions $[28,50,68-70]$. SHK is a key intermediate of the common biosynthetic aromatic pathway (Figure 1) gaining relevance as the substrate for the chemical synthesis of the drug oseltamivir phosphate, known commercially as Tamiflu ${ }^{\circ}$, an efficient inhibitor of the surface protein neuraminidase of seasonal influenza, avian influenza H5N1, and human influenza H1N1 viruses [71-74].

In addition to modifications in the SHK pathway, metabolic engineering approaches to overproduce L-TYR typically include alterations in TyrR and/or trp regulons. The TyrR regulon comprises diverse essential genes implicated in AAA biosynthesis and transport $[1,75]$. TyrR acts as a dual transcriptional activator and repressor; however, the repression mechanism requires the ATP-dependent binding of AAA to the central protein domain. L-TYR is the major effector of TyrR-mediated repression, although some repression occurs with L-PHE as co-repressor for aroF, aroL, tyrP (coding for a L-TYR specific permease), aroP (coding for an aromatic amino acid permease) and aro $G$ genes, whereas activation does not apparently involve an ATP-dependent binding of aromatic amino acids $[1,2,5,11]$. Inactivation of TyrR-mediated regulation by deletion of $t y r R$ and overexpression of $\operatorname{aro} G^{\mathrm{fbr}}$ and $\operatorname{tyr} A^{\mathrm{fbr}}$, combined with the overexpression of CCM genes (e.g. pps $A$ and $t k t A$ ) and genes of the L-TYR biosynthetic pathway (e.g. $\operatorname{tyr} B$, aro $C$, aro $A$ ) have improved the production of L-TYR in diverse $E$. coli strains $[5,11,58]$.

Similar results were obtained for L-PHE in resting cells by overexpression of a feedback-resistant or an evolved (ev) CHA mutase/prephenate dehydratase enzymes (coded by $p h e A^{\mathrm{fbr}}$ and $p h e A^{\mathrm{ev}}$, respectively) [55,76]. The bifunctional enzyme chorismate mutase/prephenate dehydrogenase TyrA, catalyzes the shared first step in L-PHE and L-TYR final biosynthetic pathways (the conversion of $\mathrm{CHA}$ to prephenate), as well as the second step in L-TYR biosynthesis (the subsequent $\mathrm{NAD}^{+}$-dependent oxidative decarboxylation of prephenate to 4-hydroxyphenylpyruvate) (Figure 1). TyrA catalyzes both reactions in separate domains of the protein and the CHA mutase/prephenate dehydrogenase is feedback-inhibited by L-TYR (up to $95 \%$ inhibition of the prephenate dehydrogenase and $45 \%$ of the CHA mutase activity) [1,2]. The bifunctional enzyme $\mathrm{CHA}$ 
Table 1 Relevant $E$. coli strains engineered for the overproduction of compounds derived from the aromatic biosynthetic pathway

Strain Relevant characteristics Main compound produced (titer

Relevant culture conditions

SP1.1pts/pSC6.090B (RB791 derivative)

$\Delta$ ptsHlcrr $\triangle$ aroK $\triangle$ aroL serA::aroB / (plasmid) arof ${ }^{\text {fbr }} t k t A, P_{\text {tac }} \operatorname{aroE~serA,~} P_{\text {tac }} g / f^{c} g / k^{c}$

AR36 (JM101 derivative)

SA116 (BW25113 derivative)

W14/pR15BABKG (W3110 derivative)

FUS4.11/pF81 kan (W3110 derivative)

BL21 (DE3)

MG1655 derivative

rpoA14 ${ }^{R}$ (K-12 derivative)

MG1655 derivative

FB-04/pSV03 (W3110 derivative)

GPT1017 (W3110 derivative)

TRTH0709/PMEL03 (MG1655 derivative)

Vio-4 (MG1655 derivative)

BKD5 (BW25113 derivative)

QH23 (ATCC 31884 derivative)

pAD-AG/AtyrR (BL21 (DE3) derivative)

VH33 $\Delta$ tyrR_DOPA (W3110 derivative)

W3110 trpD9923/pSO + pY + pAvnD

$\Delta p t$ HIlcrr $\Delta$ aroK $\Delta$ arol $\Delta l a c l \Delta p y k F /$ (plasmid) P trc aroB tktA aroG $G^{\text {fbr }}$ aroE aroD zwf

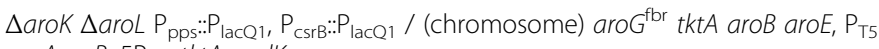
ppsA csrB, 5P tac tktA nadk

$\Delta c r r \Delta t y r A$ / (plasmid) $P_{R}$ aroG15 tyrB, $P_{L}$ pheA $A^{\text {fbr }}$ ydiB aroK yddG

$\triangle$ pheA $\triangle$ tyrA $\triangle$ arof $\triangle$ laclZYA $\triangle$ pykA $\triangle p y k F /$ (chromosome) $\mathrm{P}_{\text {tac }}$ arof aroB aroL, (plasmid) $P_{\text {tac }}$ pheA ${ }^{\text {fbr }}$ arof aroB arol

(plasmid) containing the phenylalanine dehydrogenase gene of Acinetobacter Iwoffi

(plasmid) $P_{\text {lac-Uv5 }}$ aroE aroD aroB ${ }^{\circ p}, P_{\text {L-tetO1 }}$ arof ${ }^{\text {fbr }}$ ppsA tktA, (plasmid) $P_{\text {lac-Uv5 }}$ tyrB tyra ${ }^{\text {tbr }}$ aroC, $P_{\text {trc }}$ aroA arol

$\triangle$ pheA $\triangle$ tyrR / (chromosome) $\mathrm{P} L$ tyrA $\mathrm{fbr}^{\mathrm{fbr}}$ aro $G^{\mathrm{fbr}}$, point mutations in hisH and purF, (plasmid) rpoA

$\triangle$ pheA $\triangle$ phel / (chromosome) P trc tyrA

$\Delta \operatorname{trp} R \Delta \operatorname{tnaA} \Delta$ pheA $\Delta$ tyrA / (plasmid) arof $F^{\mathrm{fbr}} \operatorname{trp} E^{\mathrm{fbr} D}$

$\Delta \operatorname{trp} R \Delta t n a A \Delta p t s G \Delta a r o P \Delta t n a B \Delta m t r /$ (chromosome) swapping of tryptophan attenuator and trp promoter by $5 \mathrm{CP}_{\text {tacs, }}$ (plasmid) aro $G^{\text {tbr }}$ trp $E^{\text {bl }}$ tkt $A$

SHK $\left(84,0.33^{\mathrm{b}}\right) .10 \mathrm{~L}$ fed-batch reactors with glucose, AAA and $15 \mathrm{~g} / \mathrm{L}$ of yeast extract

SHK $\left(43,0.42^{\mathrm{b}}\right) .1 \mathrm{~L}$ batch reactors with $100 \mathrm{~g} / \mathrm{L}$ of glucose and $30 \mathrm{~g} / \mathrm{L}$ of yeast extract

SHK $\left(3,0.33^{\text {b }}\right)$. Medium supplemented with $10 \mathrm{~g} / \mathrm{L}$ of glucose, $1 \mathrm{~g} / \mathrm{L}$ of peptone and $1 \mathrm{~g} / \mathrm{L}$ of proline

L-PHE $\left(47,0.25^{\mathrm{d}}\right) .15 \mathrm{~L}$ fed-batch reactors with

glucose and $1 \mathrm{~g} / \mathrm{L}$ of tyrosine

L-PHE $\left(13,0.15^{\mathrm{d}}\right) .15 \mathrm{~L}$ multi-phase fed-batch reactors with glycerol and lactic acid

L-PHE $\left(5,0.58^{\mathrm{d}}\right) 2 \mathrm{~L}$ batch reactors with $10 \mathrm{~g} / \mathrm{L}$ of glycerol

L-TYR $\left(2,0.44^{\mathrm{d}}\right)$. Shake flask cultures with $5 \mathrm{~g} / \mathrm{L}$ of glucose

$[28]$

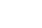

L-TYR $\left(14,0.12^{\mathrm{d}}\right) 2 \mathrm{~L}$ fed-batch reactors with glucose

L-TYR $\left(55,0.30^{d}\right) .200 \mathrm{~L}$ fed-batch reactors with glucose L-TRP $\left(13,0.10^{d}\right) .3 \mathrm{~L}$ fed-batch reactors with glucose, $2 \mathrm{~g} / \mathrm{L}$ of L-PHE and $3 \mathrm{~g} / \mathrm{L}$ of L-TYR

L-TRP (16). $5 \mathrm{~L}$ fed-batch reactors with glucose and $1 \mathrm{~g} / \mathrm{L}$ of yeast extract

L-TRP (49). $30 \mathrm{~L}$ fed-batch reactors with glucose and $1 \mathrm{~g} / \mathrm{L}$ of yeast extract

$\Delta \operatorname{trp} R \Delta \operatorname{tnaA} \Delta$ sdaA $\Delta$ lac $\Delta \operatorname{trpl} \Delta$ gal $\Delta x y l \Delta f u c /$ (chromosome) $P_{\text {tac }}$ arof aroB arol tktA serA ${ }^{\mathrm{fbr}}$ vioD ${ }^{f}$, trpe $E^{\mathrm{fbr}}$, (plasmid) vioABCE ${ }^{g}$

$\Delta p t s G \Delta$ tyrR $\triangle p y k A \Delta p y k F \Delta p h e A$ / (plasmid) Placuvs $\operatorname{aro} G^{\mathrm{fbr}} \operatorname{tyr} \mathrm{A}^{\mathrm{fbr}}$ aro $\mathrm{E}_{1} \mathrm{P}_{\mathrm{trc}}$ ppsA tktA glk, (plasmid) Placuvs T7 RNA polymerase, (plasmid) hpaBC $d$-ldh $h^{h}$ $\Delta$ phelA $\Delta$ tyra / (plasmid) $\mathrm{P}_{\mathrm{L} \text { lacol }}$ tyra ${ }^{\text {fbr }}$ ppsA tktA aroG $\mathrm{G}^{\text {tbr }}$, (plasmid) $\mathrm{P}_{\mathrm{L} \text { lacol }}$ tal, op $h p a B C$

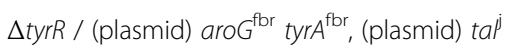

$\Delta$ ptsHlcrr / (chromosome) $P_{\text {trc }}$ galP, (plasmid) tktA P lacuv5 aroG $G^{\text {fbr }}$, (plasmid) $P_{\text {trc }}$ tyrC ${ }^{C}$ pheA

(plasmid) $\mathrm{P}_{\mathrm{L}-\mathrm{tetO}}$ ydiB aroD aro aro $^{\mathrm{fbr}}$ ppsA tktA, (plasmid) $\mathrm{P}_{\text {lacuvs }}$ tyrB tyr $\mathrm{A}^{\mathrm{fbr}}$ aroC aroA aroL, (plasmid) $P_{\text {lac Uv5 }} H C B T^{k} 4 C L 1^{\prime}$ tal

Violacein (0.7). $0.7 \mathrm{~L}$ fed-batch reactors with arabinose, $12 \mathrm{~g} / \mathrm{L}$ of tryptone and $24 \mathrm{~g} / \mathrm{L}$ of yeast extract

Salvianic acid $A\left(7,0.47^{b}\right) .0 .5 \mathrm{~L}$ fed-batch flasks with glucose and $1 \mathrm{~g} / \mathrm{L}$ of yeast extract

Caffeic acid (0.8). Shake flask cultures with $2.5 \mathrm{~g} / \mathrm{L}$ of glucose, $10 \mathrm{~g} / \mathrm{L}$ of glycerol and phenylalanine

4-coumaric acid (1). Shake flask cultures with $15 \mathrm{~g} / \mathrm{L}$ of glucose

L-DOPA $\left(1.5,0.05^{\mathrm{d}}\right) .1 \mathrm{~L}$ batch reactors with $L B$ and

$50 \mathrm{~g} / \mathrm{L}$ glucose

Avenanthramide $D\left(27^{\mathrm{e}}\right)$. Shake flask cultures with

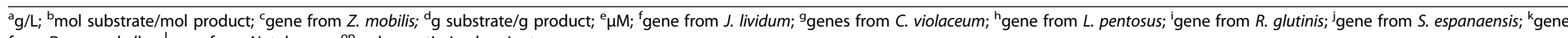
from D. caryophyllus; 'gene from N. tabacum; ${ }^{\text {op }}$ codon-optimized variant. 
mutase/prephenate dehydratase (PheA) also catalyzes the first step in the parallel biosynthetic pathways for L-TYR and L-PHE as well as the second step in L-PHE biosynthetic pathway (prephenate to phenylpyruvate) (Figure 1). The native enzyme is a dimer and each monomer contains a dehydratase active site, a mutase active site and an L-PHE binding site. PheA enzyme is inhibited by L-PHE (up to $90 \%$ of the prephenate dehydratase and $55 \%$ of the mutase activity) [1,2]. Feedback-resistant mutants of TyrA and PheA E. coli enzymes have been used for the efficient overproduction of L-TYR $[11,17,57,67]$ and L-PHE $[55,76]$ in combination with some of the previously described alterations in CCM and the SHK pathway (Table 1). An alternative approach to take advantage of the natural feedback-resistant diversity in the TyrA enzyme family was the expression of the $\mathrm{TyrC}^{\mathrm{fbr}}$ enzyme (cyclohexadienyl dehydrogenase) from $Z$. mobilis and the CHA mutase domain of native PheA from E. coli, relieving rate-limiting steps and increasing the carbon flux towards L-TYR [57].

A strategy to minimize carbon loss to competing pathways was exemplified in the CHA node with the construction of L-PHE production strains expressing TyrA enzymes containing tags for increased proteolytic degradation, instead of completely removing the enzyme. The resultant strains have the advantage of not being auxotrophic to L-TYR while displaying a higher L-PHE/L-TYR production ratio than the strain containing the wild-type TyrA [77].

Additional modifications applied in L-TRP overproducers include the overexpression of exporter protein YddG $[61,78,79]$, the inactivation of permeases AroP, Mtr and TnaB to avoid re-internalization $[61,79,80]$, the deletion of gene tnaA coding for a tryptophanase to avoid product degradation $[59,81,82]$ and expression of genes included in the tryptophan biosynthetic branch, including a feedback-resistant version of anthranilate synthase, $\operatorname{Trp} E^{\mathrm{fbr}}[60,81]$.

Variations on the strategies described in this section have also been applied to the production of other valuable compounds derived from the AAA pathway such as phenyllactate, phenylacetate and phenylethanol [83], L-DOPA [84], mandelic acid [85], deoxyviolacein and violacein $[82,86]$, avenanthramides [87], and resveratrol [88] (Table 2).

\section{Increasing the genetic engineering repertoire: development and application of synthetic biology strategies and techniques}

The field of synthetic biology has been continuously evolving and it is now acknowledged that this discipline is primarily concerned with the design and characterization of biological parts $[89,90]$. Indeed, modular and predictable parts find many applications in the modification of cellular metabolism, whether these alterations are direct (modulation of the expression and function of enzymes comprised in metabolic pathways) or indirect (rewiring and repositioning of sensing components and cellular effectors). In this sense, the powerful recent advances in synthesis and assembly of macromolecules have changed the way to approach challenges in metabolic engineering. This has helped to generate a degree of biological diversity and reprogramming not previously reached with traditional biological controllers, promoting the merging of rational and combinatorial approaches to direct cellular design [91,92].

The aromatic biosynthetic pathway in E. coli was no exception to this paradigm shift, resulting in notable accomplishments over the last years. It is worth noting that even when the upregulation of a few genes can increase the carbon flux from CCM towards the aromatic biosynthetic pathway, the outcome is importantly influenced by a variety of factors, such as the combination of expression modules, genetic background and cultivation conditions. It is therefore ideal to design experiments to obtain a characterization of the contribution of each factor to the phenotype. Illustrative examples on this subject include the assessment of differences in the production of L-TYR by overexpressing various sets of genes in a stepwise approach (Table 1) [58,93].

The generation of synthetic parts in a faster, cheaper and more targeted way has also enabled metabolic engineers to reach unprecedented biochemical diversity, exemplified by the production of plant compounds using precursors present in the aromatic biosynthetic pathway in E. coli. In this way, combinations of simultaneous transcriptional modules and genetic platforms have resulted in strains with the ability to produce attractive compounds such as salvianic acid A [94], $\delta$-tocotrienol and its intermediate 2-methyl-6-geranylgeranyl-benzoquinol $[95,96]$ (Figure 2) and (S)-reticuline [97] (Figure 3).

Aside from the product titers reached so far, these approaches are appealing because the systematic evaluation of conditions permits a more precise identification of targets for future improvement. In this respect, more structurally complex compounds can be produced by the optimization of expression parameters, for example when approaching problems with the heterologous insertion of genes and pathways into E. coli. One successful case concerning a systematic analysis of heterologous expression is the production of (2S)-pinocembrin from glucose as the only carbon source [98] (Figure 2). In this report, the authors assembled gene expression modules, including genes from the SHK pathway as well as heterologous sources. With this arrangement it was possible to accumulate up to $40 \mathrm{mg} / \mathrm{L}$ of (2S)-pinocembrin, even when using four plasmids and enzymes with naturally low catalytic efficiencies. The same system was used to evaluate the capabilities for resveratrol production after 
Table 2 Proposed applications of high-valued compounds derived from the aromatic pathway and synthesized by engineered $E$. coli strains

\begin{tabular}{|c|c|c|}
\hline Compound & Summary of pharmaceutical and industrial applications & References \\
\hline $\begin{array}{l}\text { Shikimate ((3R,4S,5R)-3,4,5-trihydroxycyclohexene-1- } \\
\text { carboxylic acid) }\end{array}$ & $\begin{array}{l}\text { Antipyretic, antioxidant, anticoagulant, antithrombotic, anti-inflammatory, and } \\
\text { analgesic agent. Has a key role in the synthesis of important pharmacological } \\
\text { compounds such as anti-cancer and antibacterial agents, as well as hormones. } \\
\text { Substrate in the chemical synthesis of the antiviral Tamiflu }{ }^{\circledast} \text {. }\end{array}$ & {$[72,74]$} \\
\hline
\end{tabular}

Salvianic acid or danshensu (3,4-dihydroxyphenyllactic acid) A naturally occurring plant polyphenolic acid, considered as a superior antioxidant. Its scavenging activities against free hydroxyl radicals and superoxide anion radicals are higher than vitamin C. Has a variety of other pharmacological effects, including improving cerebral blood flow, inhibiting platelet activation and arterial thrombosis, as well as anti-cancer and anti-inflammatory effects.

(2S)-pinocembrin (5,7-dihydroxyflavanone)

Flavonoid with demonstrated activity decreasing the neurological scores, alleviating brain edema, reducing the permeability of blood-brain barrier and alleviating cerebral ischemic injury in the middle cerebral artery occlusion in rats. Has been proposed as a novel therapeutic agent to reduce cerebral ischemia/reperfusion and blood-brain injury, useful for its antioxidant and anti-apoptotic effects.

Caffeic acid (3,4-dihydroxycinnamic acid)

Possesses various pharmacological activities including antioxidant, antitumoral, antiviral, antidepressive and antidiabetic functions.

Resveratrol (3,4',5-trihydroxystilbene)

Potential therapeutic effects in humans as antioxidant, anti-inflammatory, anticancer, and chemopreventive agent

Violacein ((3E)-3-[5-(5-hydroxy-1H-indol-3-yl)-2-oxo-1Hpyrrol-3-ylidene]-1H-indol-2-one) and deoxyviolacein

Activity against herpes simplex virus and pathogenic bacteria such as Staphylococcus aureus and Pseudomonas aeruginosa. Violacein has shown successful activity against leukemia, lung cancer, human uveal melanoma and lymphoma cells, where it mediates apoptosis. It is also an interesting bio-dye showing attractive color tone and stability.

PDC (2-pyrone-4,6-dicarboxylic acid) Proposed as a novel starting material for several useful synthetic polymers such as polyesters and polyamides.

(S)-reticuline ((1S)-1-[(3-hydroxy-4-methoxyphenyl)methyl]6-methoxy-2-methyl-3,4-dihydro-1H-isoquinolin-7-ol)

Building block for benzylisoquinoline alkaloids, including the analgesic compounds morphine and codeine, as well as the antibacterial agents berberine and palmatine. Useful in the development of novel antimalarial and anticancer drugs.

Hydroxytyrosol (3,4-dihydroxyphenylethanol) Powerful antioxidant activity. Potential antitumoral, antiatherogenic, anti-inflammatory and antiplatelet aggregation agent.

Avenanthramides

Natural hydroxycinnamoyl anthranilates with antioxidant, anti-inflammatory, and antiproliferative effects, considered to contribute to the health benefits of oatmeal consumption. Potential antitumor activities.

$\delta$-tocotrienol

slight modifications were introduced to increase malonylCoA and L-TYR availability. This work revealed large variations in the concentration of produced metabolites with respect to small variations in the genetic constructs [99] (Figure 2). In a similar approach, the introduction of a foreign pathway succeeded in deviating carbon flow from 3-dehydroshikimate towards the synthesis of 2-pyrone4,6-dicarboxylic acid (PDC) (Figure 3). Strains overexpressing six different genes from three different plasmids were able to produce the desired compound with a $17.3 \%$ yield from glucose [100].

It is also interesting to consider other strategies to generate and screen metabolic diversity, such as modifications of the global transcription machinery coupled to high-throughput screening for metabolite production
$[101,102]$. By merging these approaches with combinatorial techniques for gene overexpression, a $114 \%$ increase in L-TYR production from a previously engineered strain was reported [101].

Strains with the capability to overproduce L-TYR from simple carbon sources have been used as a backbone for production of more structurally complex compounds. For example, the construction of codon-optimized heterologous gene clusters with a wide span of strengths in promoter and ribosome binding sequences (RBS) has allowed the generation of $E$. coli strains capable of producing phenylpropanoic acids such as caffeic acid, coumaric acid and ferulic acid [103-105] (Figure 2), as well as hydroxycinnamoyl anthranilates [87] and other derivatives, such as hydroxytyrosol [106] (Figure 3). Another combinatorial 


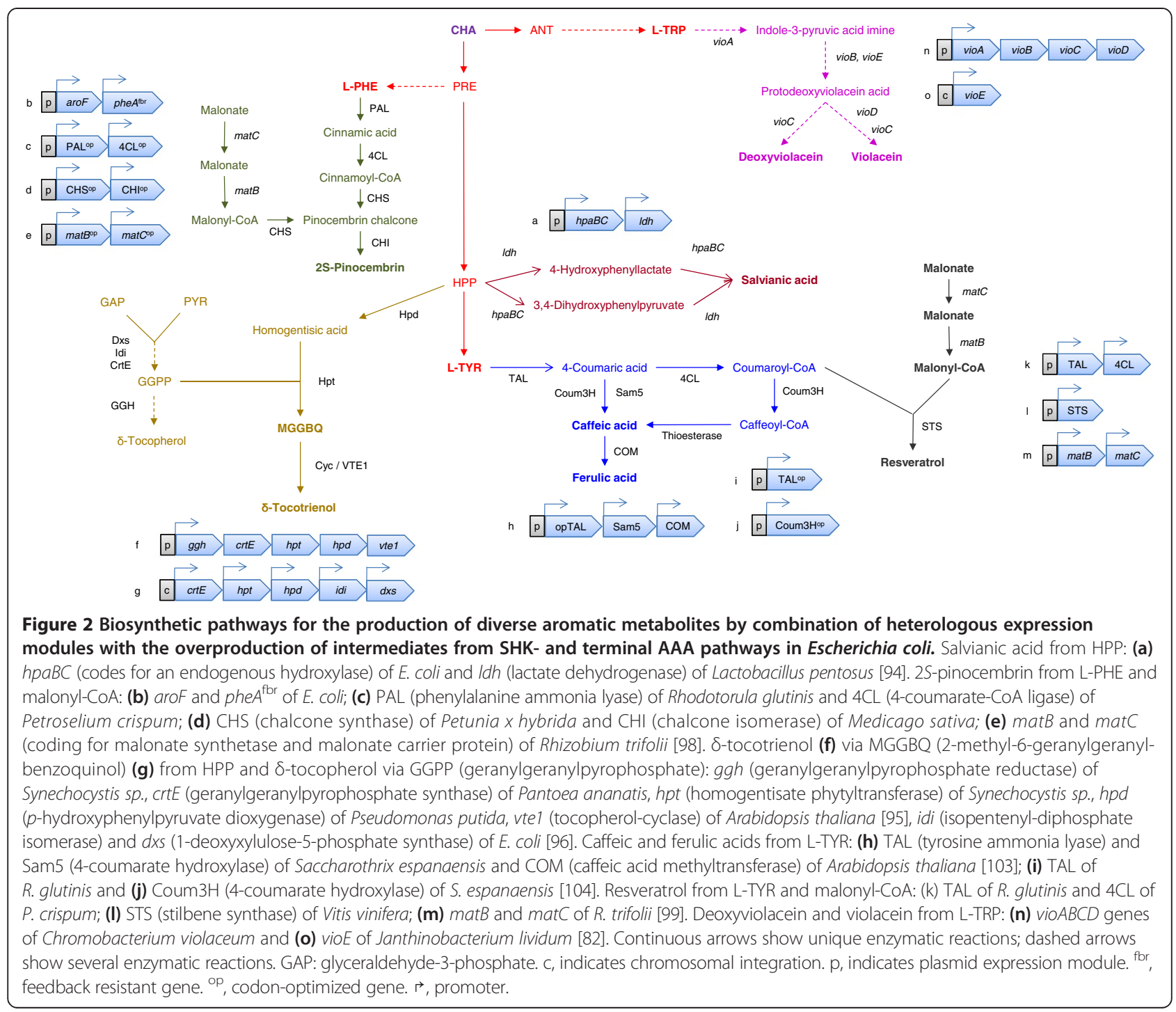

technique applied in the generation and isolation of strains with an increased production of indigo (a compound that can be obtained from the L-TRP biosynthetic intermediate indole) is coselection MAGE (multiplex automated genome engineering). This method relies on a cyclical oligo-mediated allelic replacement to modify genomic targets [107] that was later improved by linking the process with the recovery of an inactivated selection marker, enhancing the size and efficiency of insertions [108]. With this approach, the authors were able to insert $\mathrm{T} 7$ promoters upstream of 12 genes or operons associated with the AAA pathway in a strain modified to produce indigo and recovered 80 unique derivatives with variable promoter insertions. As a result, it was possible to identify strains with more than a fourfold improvement in indigo production over the ancestor strain, as well as synergetic interactions of expressed genes [108].
The application of synthetic RNA devices with the goal of increasing AAA production in E. coli has recently attracted attention. In particular, artificial riboswitches coupling the binding of L-TRP to growth under a selective pressure have been constructed and tested in vivo. By modulating the expression of gene aroG under this scheme, strains with superior capabilities for L-TRP production could be linked to the increased growth rates after rounds of selective improvement [109]. In another report, a synthetic sRNA library was constructed for targeted gene expression silencing. The authors demonstrated the applicability of this approach in the production of L-TYR with the plasmid-based expression of genes ppsA, tktA, aroF, aroK, tyrC, aroG and tyrA, and the simultaneous silencing of genes $t y r R, c s r A$, pgi and $p p c$ in several $E$. coli strains. With an easily transferrable gene-regulation platform, the combination of expression levels and genetic backgrounds led to the selection of a strain that can 


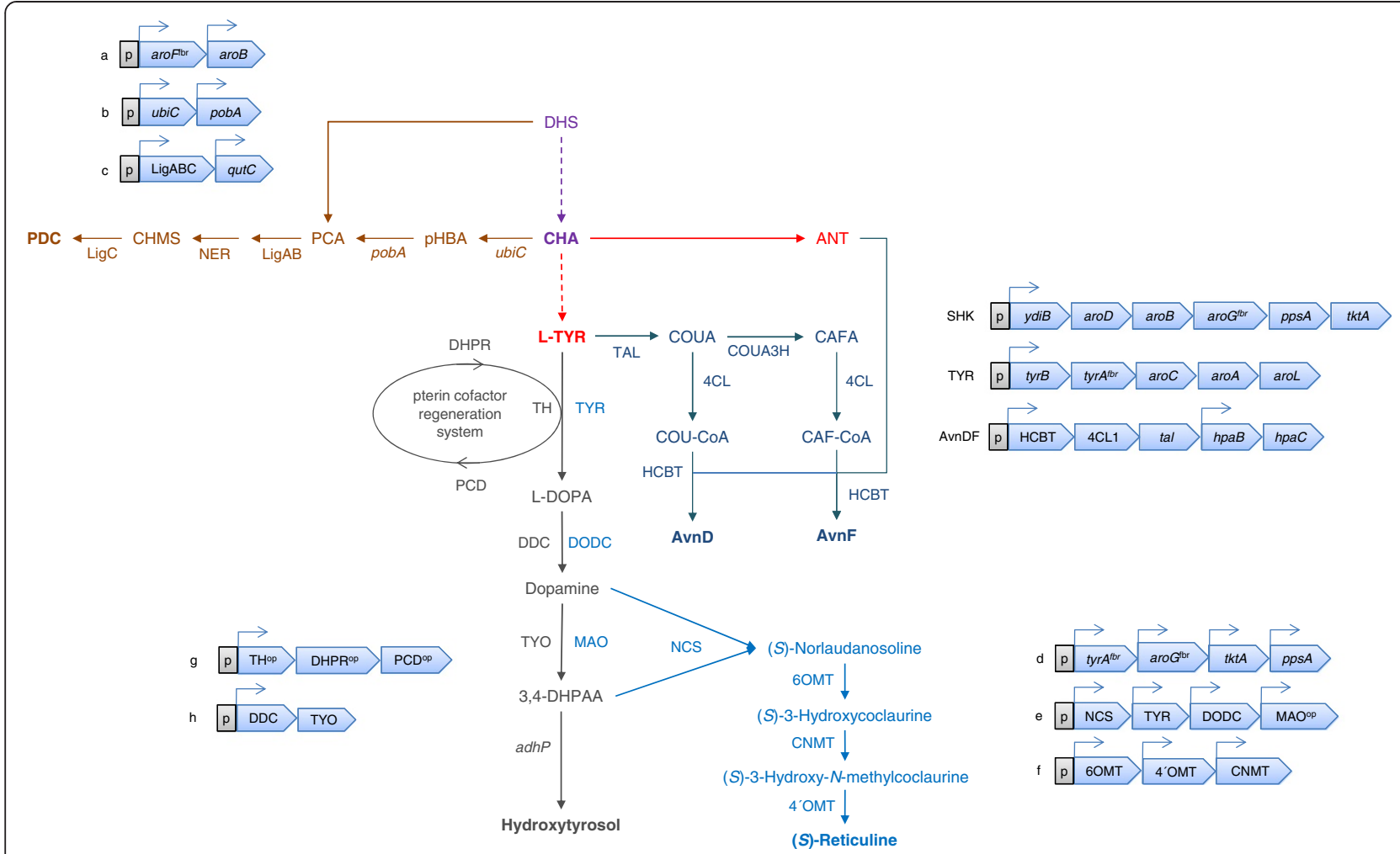

Figure 3 Biosynthetic pathways for the production of diverse aromatic metabolites by combination of heterologous expression modules with the overproduction of intermediates from SHK- and terminal L-TYR pathways in Escherichia coli. PDC (2-pyrone-4,6dicarboxylic acid) from DHS and CHA: (a) arof fbr and $\operatorname{aroB}$ of E. coli; (b) ubiC (chorismate pyruvate-lyase) and pobA (4-hydroxybenzoate hydroxylase) of E. coli and Pseudomonas putida, respectively; (c) LigAB (protocatechuate 4,5-dioxygenase) and LigC (CHMS dehydrogenase) of Sphingobium sp. SYK-6 and qutC (dehydroshikimate dehydratase) of Emericella (Aspergillus) nidulans [100]. (S)-Reticuline from L-TYR: (d) tyra ${ }^{\text {fbr }}$, aroG $G^{\mathrm{fbr}}$, tktA and ppsA of E. coli; (e) NCS (norcoclaurine synthetase) of Coptis japonica, TYR (tyrosinase) of Streptomyces castaneoglobisporus, DODC (DOPA decarboxylase) of Pseudomonas putida and MAO (monoamine oxidase) of Micrococcus luteus; (f) 6OMT (norcoclaurine 6-0-methyltransferase), 4'OMT (3'-hydroxy-N-methylcoclaurine 4'-O-methyltransferase) and CNMT (coclaurine-N-methyltransferase) of C. japonica [97]. Hydroxytyrosol from L-TYR via 3,4-DHPAA (3,4-dihydroxyphenylacetaldehyde): (g) PCD (pterin-4 alpha-carbinolamine dehydratase) and DHPR (dihydropteridine reductase) of human and TH (tyrosine hydroxylase) of mouse; (h) DDC (L-DOPA decarboxylase) of pig and TYO (tyramine oxidase) of M. luteus [106]. Avenanthramides AvnD [N-(4'-hydroxycinnamoyl)-anthranilic acid] and AvnF [N-(3',4'-dihydroxycinnamoyl)-anthranilic acid] from L-TYR and ANT: AvnDF module, tal (tyrosine ammonia-lyase) of Rhodotorula glutinis, 4CL1 (4-coumarate-CoA ligase) of Nicotiana tabacum, COUA3H (SAM5) (p-coumarate 3-hydroxylase) of Saccharothrix espanesis, HCBT (hydroxycinnamoyl/benzoyl-CoA/anthranilate N-hydroxycinnamoyl/benzoyltransferase) of Dianthus caryophyllus and hpaBC (code for an endogenous hydroxylase) of E. coli. SHK and TYR modules contain endogenous genes of $E$. coli [56]. PCA (protocatechuate); CHMS (4-carboxy-2-hydroxymuconate-6-semialdehyde); CAFA (caffeate); CAF-CoA (caffeoyl-CoA); COUA (p-coumarate); COU-CoA (p-coumaroyl-CoA); adhP (alcohol dehydrogenase of E. coli). p, indicates plasmid expression module. ${ }^{\text {fbr }}$, feedback resistant gene. ${ }^{\circ}$, codon-optimized gene. $\gg$, promoter. NER, Non-enzymatic reaction.

accumulate up to $21.9 \mathrm{~g} / \mathrm{L}$ of L-TYR in high-density cultures [110].

\section{Integration and application of data: systems-based approaches to the production of AAA}

Even with the relative success obtained so far regarding the overproduction of aromatic compounds in E. coli, insights into the global metabolic state of engineered strains under production conditions are still scarce. Moreover, the effects of targeted strain modifications are typically underestimated, since they do not always result in significant differences in cell growth or production of specific metabolites. Combination of techniques such as genomics, transcriptomics, proteomics, metabolomics and fluxomics can unravel the particular cellular state during a defined condition by providing snapshots of different levels of metabolism [111]. However, in order to turn this information into knowledge of new potential engineering targets, adequate comparisons must be established. Since it is not trivial to define the type and extent of data to be extracted and compared, systems biology approaches are needed to manage holistic information at different levels of cellular functions [112,113].

Although the systematic integration of -omics approaches have been applied to characterize and reverse engineer bacterial strains producing several amino acids [6,114-117], 
there are still relatively few reports on the use of these techniques with AAA overproducers. For example, one study reports the effect of inactivating genes coding for PEP-consuming enzymes (PTS, PykF and PykA) over the flux distributions in the central carbon metabolism as an attempt to increase the availability of this AAA precursor [33]. The net result of either inactivation was a flux increase to biomass formation pathways, but several differences on important CCM nodes were also found between all conditions. Furthermore, PTS inactivation revealed a carbon recycling response between PEP and OAA combined with a reduced glycolytic flux. When these strains were transformed with plasmids encoding enzymes to promote the production of L-PHE, a 19-, 14-, and 25- fold increase on the yield of this amino acid was observed for the PTS, $\mathrm{PTS}^{-} p y k A$, and $\mathrm{PTS}^{-}$ pykF mutants, respectively [33].

Targeted proteomics and metabolite profiling analyses are also very valuable to provide feedback about expression systems used in the production of AAA. One report describes such approaches on a collection of L-TYR producing strains with different gene-expression arrays, allowing the authors to identify and improve sub-optimally expressed genes. After a second engineering round of the synthetic expression modules a strain was constructed which can produce L-TYR from glucose with $80 \%$ of the theoretical yield, estimated as $0.55 \mathrm{~g} / \mathrm{g}$ in strains with a functional PTS [58]. A related work characterized the impact on SHK pathway enzyme levels resulting from the removal of TyrR regulator, along with the use of a feedback-resistant TyrA and deletion of the pheA gene on L-TYR producing strains. The results showed that small changes in protein levels caused by the genetic alterations can have a big impact on metabolite production, as a 250 -fold span of L-TYR concentrations were detected [118]. A different work found many proteins differentially expressed as a response to the sole inactivation of the $p y k F$ gene, including DAHP synthase (AroG), SHK dehydrogenase (AroE), SHK kinase I (AroK), CHA synthase (AroC), prephenate dehydratase (PheA), anthranilate synthase (TrpD, TrpE) and L-TRP synthase (TrpA), as compared to the wild type strain [119].

In another example, transcriptional analysis and whole genome sequencing studies were performed on L-TYR producing strains obtained by combinatorial and targeted approaches, coupled to high-throughput screening, in an attempt to discover the changes that led to higher L-TYR production [101]. The transcriptional analysis revealed upregulation of genes related to acid stress resistance and global reductions in the expression of several pathways such as ribosomal protein and RNA formation, fatty acid elongation, de novo purine/pyrimidine biosynthesis and DNA replication, which imply a cellular shift from proliferation and growth to maintenance and stress survival. Genomic analyses revealed differential single base-pair changes between the studied strains. When these mutations were reintroduced on a parental strain background higher L-TYR production was observed, showing their contributions to the overproduction phenotype. Finally, a reverse engineered strain was constructed, which gave a titer of $902 \mathrm{mg} / \mathrm{L}$ and an L-TYR yield on glucose of $0.18 \mathrm{~g} / \mathrm{g}$ on a genetically-defined background [101]. Other works have also characterized the global transcriptional response to the presence of high levels of L-PHE or SHK in simple and complex media $[120,121]$ or starvation conditions [122], revealing metabolic information that can be used for further improvement of the strains and cultivation conditions.

Along with data obtained by high-throughput systems, modeling of metabolism by mathematical approaches has become an important tool for analyzing cell responses and unravel the metabolic regulation between the cell information/control systems [111]. Moreover, genome-scale models of metabolism have been analyzed by constraint-based approaches [123]. Gene deletion effects over flux distributions have also been studied in order to find the combination that provides the best metabolic performance on a given condition. For example, the deletion impact of 1261 genes was modeled using a reconstruction of biochemical interactions, resulting in 195 genes exerting high impact on flux distributions in various metabolic subsystems [124]. A strategy developed to circumvent the need for kinetic parameters of enzymes present in a metabolic network is ensemble modeling, which uses phenotypic data obtained from overexpression and deletion of enzymes to screen out flux distributions from an initial ensemble of solutions derived from elementary reaction models [125]. This method has been used to model the AAA pathway for DAHP production with data obtained from the overexpression of CCM genes. A subset of flux distributions was found capable of describing the phenotypic characteristics of the strains and rendered information about the kinetic and stoichiometric limitations around PEP and E4P nodes [125]. As more genomic, transcriptomic and proteomic functional interactions continue to be unraveled, similar approaches will become powerful tools to model specific metabolic outcomes related to AAA biosynthesis.

\section{Bioprocess engineering: optimization of AAA compound production}

In order to create economically viable products, the processes developed and tested at laboratory scale have to be adapted to larger operational volumes. Although engineered strains should ideally perform equally in $1 \mathrm{~L}$ scale as in industrial scales (going from 500-10,000 L for fine chemicals to more than $100,000 \mathrm{~L}$ for commodity chemicals), a significant reduction in performance as a result of scale-up is often observed [126]. Therefore, it 
is important to apply strategies to prevent physiological changes caused by heterogeneities of fermentation parameters during scale-up processes with $E$. coli. Stress-mediated cellular responses to chemical and physical factors can negatively impact as much as $60 \%$ over the productivity, the biomass and product yields when a strain is exposed to large-scale production conditions [127,128].

Fed-batch cultivations have been a popular method to produce aromatic compounds since they promote high cellular densities, offer tight control over the $\mu$ and substrate concentrations, and permit a better management of dissolved oxygen tension (DOT) to prevent the activation of fermentative pathways $[16,129]$. In one example, a fed-batch strategy improved violacein production from arabinose (through an expanded pathway from L-TRP) by adjusting the $\mu$ at $0.011 \mathrm{~h}^{-1}$ [82]. With this procedure, cellular concentrations with optical density values up to 70 were reached, producing $710 \mathrm{mg} / \mathrm{L}$ of violacein and avoiding acetate accumulation in the medium, a known inhibitor of growth and pigment production.

Another work studied the impact of different feeding strategies over the production of L-TRP in a recombinant strain [16]. An increase in the volumetric productivity of this compound was reached by a novel feeding strategy with a highly concentrated glucose solution (800 g/L) after the exhaustion of the initial glucose. By using a combined pseudo-exponential feeding at the exponential phase and a glucose-stat feeding after the exponential phase, an efficient control over the $\mu$ was achieved (below the acetic acid production threshold), reaching $38.8 \mathrm{~g} / \mathrm{L}$ of L-TRP. This represented an increase of $19.9 \%$ due to reduced acetic acid accumulation [16].

Even if feeding strategies can cope to some extent with the problems derived from acetic acid production, a combination of these with genetic modifications has also been tested for the production of aromatic compounds. In a recent report, the effect of inactivating the gene coding for the enzyme phosphotransacetylase (Pta) over the production of L-TRP was assessed. By combining this modification with the use of a DO-stat for controlling inflow rate at a suitable DOT, the authors were able to increase the production of L-TRP and biomass while maintaining the growth rate and reducing the accumulation of acetic acid [129].

Substrate characteristics can also be optimization variables for the production of AAA pathway intermediates. One example is the evaluation of glycerol for L-PHE production $[130,131]$. The low cost of glycerol coupled with its higher degree of carbon reduction when compared to other sugars such as glucose, could result in high energy yield per carbon and hence be advantageous for AAA production processes. However, it is important to characterize the influence of fermentation parameters such as DOT, temperature and $\mathrm{pH}$, as well as the availability of substrates, over the growth and product formation rates. In one report, variations in oxygen supply (by changing aeration rates and impeller speeds) were tested over the L-PHE production capabilities of a recombinant strain growing on glycerol [130]. With this approach, a direct correlation between biomass and L-PHE production rates were found at impeller speeds up to $400 \mathrm{rpm}$, being this the maximum operational value before shear stress starts to diminish strain capabilities. After setting the impeller speed to $400 \mathrm{rpm}$, aeration optimization resulted in the highest product yield obtained, $0.58 \mathrm{~g} / \mathrm{g}$, which is $20 \%$ higher than the yields obtained before optimization of oxygen supply. Interestingly, the authors report this high yield with a strain in which the only recombinant measure taken is the heterologous expression of a phenylalanine dehydrogenase gene [130]. On the other hand, another group has recently reported the production of $13 \mathrm{~g} / \mathrm{L}$ of L-PHE from glycerol and a yield of $0.15 \mathrm{~g} / \mathrm{g}$ using a multi-phase fed-batch process with a strain containing several genetic modifications [131] (Table 1).

Product characteristics should also be taken into account when developing an efficient bioprocess. For example, L-TYR exhibits low solubility in typical fermentation conditions, triggering its precipitation when saturation is reached. This characteristic would normally be beneficial for a fermentation process, as a precipitated compound can be easily recovered and it is not expected to affect strain physiology and production capabilities. Interestingly, one report described that the L-TYR crystals can stabilize foam, causing operational problems during fermentation [17]. Consequently, this foaming process was studied on 10 and $200 \mathrm{~L}$ fed-batch fermentations for L-TYR production to assess the effect of $\mathrm{pH}$, antifoam concentration, cooling rate, L-PHE concentration and seeding level on foam production. It was determined that high concentrations of L-PHE or antifoam, as well as low $\mathrm{pH}$ and low seeding, are the preferred conditions to avoid detrimental foaming production. With this approach it was possible to produce L-TYR from glucose with a yield of $0.3 \mathrm{~g} / \mathrm{g}$ and titers as high as $55 \mathrm{~g} / \mathrm{L}$ on a $200 \mathrm{~L}$ scale [17]. Moreover, this study revealed important data for the design of an economically feasible process for the production of L-TYR.

Process optimization could also be concerned with an enhancement of the strain ability to withstand high concentrations of aromatic compounds, not only for toxic final products but for harmful intermediates or byproducts, which often accumulate as a consequence of the suboptimal alleviation of control levels in the biosynthetic pathways. This is a commonly-encountered problem with many of the intermediates and final products in the AAA. For example, one group reported the optimization of L-TRP production by modifying the export 
and import capabilities of a modified strain in order to minimize its intracellular concentration and avoid feedback control by product accumulation [79]. This group constructed a strain featuring the plasmid-based overexpression of the AAA exporter YddG, resulting in a production increase of $12.6 \%$ compared to the parental strain on a $30 \mathrm{~L}$ fermentation. Another example of the successful combination of genetic and fermentation procedures involves the construction of a strain for L-PHE overproduction with a PTS-independent glucose transport and expression of feedback-resistant versions of AroG and PheA. By overexpressing genes $y d i B$, aroK and $\operatorname{tyr} B$ with a temperature-dependent system, as well as $y d d G$ in a TyrA ${ }^{-}$ background, the authors were able to produce up to $47 \mathrm{~g} / \mathrm{L}$ of L-PHE with a yield of $0.25 \mathrm{~g} / \mathrm{g}$ from glucose in a $15 \mathrm{~L}$ fed-batch process [132].

Finally, bioprocess design is also an important factor in optimization of the production of aromatic pathway derivatives. The bioconversion of phenylpyruvate (PPN) to L-PHE was studied with an immobilized cell bioprocess [133]. This technique has several advantages such as the ability to reuse the immobilized cells, the capacity to utilize high cell densities and improved stability of the system. For example, a mixed-gel surface composed of k-carrageenan and gelatin, together with the optimization of its composition to enhance the mechanical strength and reduce the toxicity and solidification point was used as biomass carrier for the production of L-PHE [133]. Studies on the effect of $\mathrm{pH}$, temperature, $\mathrm{Mg}^{+2}$ and trehalose presence resulted in the implementation of a process showing an improvement of $80 \%$ on the L-PHE conversion from PPN after 15 successive batch experiments.

\section{Conclusions}

The present review aims to provide a panorama of the current achievements and newly found goals related to the production of aromatic compounds in E. coli. The AAA pathway and the metabolic changes resulting from its deregulation have attracted the interest of metabolic engineers for many years and remain important research targets on several organisms. It is evident that the establishment of efficient bioprocesses on this topic requires the design and implementation of multidisciplinary strategies, taking advantage of the fast-paced developments coming from nearly all biotechnological fields but particularly from those related with information technologies, such as systems and synthetic biology. The works compiled here are a good example of the benefits obtained when new ideas and viewpoints are introduced to an established field in order to cope with long-known problems. From the comparisons presented, it is noticeable that the use of rational and combinatorial approaches powered by the ability to develop complex genetic circuits and highthroughput screenings of new producers has set new trends when dealing with the production of aromatic compounds in E. coli. The benefits of the integral application of these technologies can already be observed, not only from the improved production processes for AAA and pathway intermediates with large and established markets, but also with the generation of novel derivative compounds with important pharmaceutical applications.

\section{Competing interests}

The authors declare that they have no competing interests.

\section{Authors' contributions}

All authors participated in the preparation of this contribution. AR had a major role in writing and editing the manuscript. All authors have read and approved the final version.

\section{Acknowledgements}

This work was supported by CONACYT 105782, 177568 and DGAPA-PAPIIT UNAM IN206812 grants.

Received: 30 May 2014 Accepted: 17 August 2014

Published online: 09 September 2014

\section{References}

1. Keseler IM, Mackie A, Peralta-Gil M, Santos-Zavaleta A, Gama-Castro S, Bonavides-Martinez C, Fulcher C, Huerta AM, Kothari A, Krummenacker M, Latendresse M, Muniz-Rascado L, Ong Q, Paley S, Schroder I, Shearer AG, Subhraveti P, Travers M, Weerasinghe D, Weiss V, Collado-Vides J, Gunsalus RP, Paulsen I, Karp PD: EcoCyc: fusing model organism databases with systems biology. Nucleic Acids Res 2013, 41:D605-D612.

2. Sprenger G: Aromatic Amino Acids. In Amin Acid Biosynth - Pathways, Regul Metab Eng. Edited by Wendisch VF. Berlin, Heidelberg: Springer; 2007:418 [Microbiology Monographs, vol. 5].

3. Herrmann KM, Weaver LM: The shikimate pathway. Annu Rev Plant Biol 1999, 50:473-503.

4. Richards TA, Dacks JB, Campbell SA, Blanchard JL, Foster PG, McLeod R, Roberts CW: Evolutionary origins of the eukaryotic shikimate pathway: gene fusions, horizontal gene transfer, and endosymbiotic replacements. Eukaryot Cell 2006, 5:1517-1531.

5. Lütke-Eversloh T, Santos CNS, Stephanopoulos G: Perspectives of biotechnological production of L-tyrosine and its applications. App/ Microbiol Biotechnol 2007, 77:751-762.

6. Becker J, Wittmann C: Systems and synthetic metabolic engineering for amino acid production - the heartbeat of industrial strain development. Curr Opin Biotechnol 2012, 23:718-726.

7. Ikeda M, Takeno S: Amino acid production by Corynebacterium glutamicum. In Corynebacterium glutamicum. Volume 23. Edited by Yukawa H, Inui M. Berlin, Heidelberg: Springer Berlin Heidelberg; 2013:107-147.

8. Ajinomoto Co. Inc: FY2013 Market and Other Information. 2014

9. Li Z, Ji X, Kan S, Qiao H, Jian M, Lu D, Wang J, Huang H, Jia H, Ouyuang P, Ying $\mathrm{H}$ : Past, Present and Future Industrial Biotechnology in China. In Biotechnol China II Chem Energy Environ. Edited by Tsao GT, Ouyang P, Chen J. Berlin, Heidelberg: Springer; 2010:1-42.

10. Bongaerts J, Krämer M, Müller U, Raeven L, Wubbolts M: Metabolic engineering for microbial production of aromatic amino acids and derived compounds. Metab Eng 2001, 3:289-300.

11. Sprenger GA: From scratch to value: Engineering Escherichia coli wild type cells to the production of L-phenylalanine and other fine chemicals derived from chorismate. Appl Microbiol Biotechnol 2007, 75:739-749.

12. Pittard J, Yang J: Biosynthesis of the Aromatic Amino Acids. Eco Sal Plus 2008, 1.

13. Orth JD, Conrad TM, Na J, Lerman JA, Nam H, Feist AM, Palsson BØ: A comprehensive genome-scale reconstruction of Escherichia coli metabolism-2011. Mo/ Syst Biol 2011, 7.

14. Klein-Marcuschamer D, Santos CNS, Yu H, Stephanopoulos G: Mutagenesis of the bacterial RNA polymerase alpha subunit for improvement of complex phenotypes. Appl Environ Microbiol 2009, 75:2705-2711.

15. Jeong J, Cho N, Jung D, Bang D: Genome-scale genetic engineering in Escherichia coli. Biotechnol Adv 2013, 31:804-810. 
16. Cheng L-K, Wang J, Xu Q-Y, Xie X-X, Zhang Y-J, Zhao C-G, Chen N: Effect of feeding strategy on L-tryptophan production by recombinant Escherichia coli. Ann Microbiol 2012, 62:1625-1634.

17. Patnaik R, Zolandz RR, Green DA, Kraynie DF: L-Tyrosine production by recombinant Escherichia coli : Fermentation optimization and recovery. Biotechnol Bioeng 2008, 99:741-752.

18. Ikeda M: Amino acid production processes. In Microb Prod L-amino acids. Berlin, Heidelberg: Springer; 2003:1-35.

19. Gosset G: Production of aromatic compounds in bacteria. Curr Opin Biotechnol 2009, 20:651-658.

20. Westerhoff HV, Palsson BO: The evolution of molecular biology into systems biology. Nat Biotechnol 2004, 22:1249-1252.

21. Blazeck J, Alper H: Systems metabolic engineering: Genome-scale models and beyond. Biotechnol J 2010, 5:647-659.

22. Postma PW, Lengeler JW, Jacobson GR: Phosphoenolpyruvate: carbohydrate phosphotransferase systems of bacteria. Microbiol Rev 1993, 57:543-594.

23. Gosset G: Improvement of Escherichia coli production strains by modification of the phosphoenolpyruvate: sugar phosphotransferase system. Microb Cell Fact 2005, 4:14.

24. Escalante A, Salinas-Cervantes A, Gosset G, Bolívar F: Current knowledge of the Escherichia coli phosphoenolpyruvate-carbohydrate phosphotransferase system: peculiarities of regulation and impact on growth and product formation. Appl Microbiol Biotechnol 2012, 94:1483-1494.

25. Sauer U, Eikmanns BJ: The PEP - pyruvate - oxaloacetate node as the switch point for carbon flux distribution in bacteria. FEMS Microbio/ Rev 2005, 29:765-794

26. Sprenger G, Siewe R, Martin K, Sonke T: Microbial Preparation of Substances from Aromatic Metabolism/l. WO patent 98/18936. 1998.

27. Frost JW, Knop DR: Biocatalytic Synthesis of Shikimic Acid. US patent $6,472,169$ B1. 2002

28. Chandran SS, Yi J, Draths KM, Von Daeniken R, Weber W, Frost JW: Phosphoenolpyruvate availability and the biosynthesis of shikimic acid. Biotechnol Prog 2003, 19:808-814.

29. Yi J, Draths KM, Li K, Frost JW: Altered glucose transport and shikimate pathway product yields in E. coli. Biotechnol Prog 2003, 19:1450-1459.

30. Balderas-Hernandez VE, Sabido-Ramos A, Silva P, Cabrera-Valladares N, Hernandez-Chavez G, Baez-Viveros JL, Martinez A, Bolivar F, Gosset G: Metabolic engineering for improving anthranilate synthesis from glucose in Escherichia coli. Microb Cell Fact 2009, 8:19.

31. Flores N, Xiao J, Bolivar F, Valle F: Pathway engineering for the production of aromatic compounds in Escherichia coli. Nat Biotechnol 1996, 14:620-623.

32. Valle F, Mejia N, Berry A: Application of Glucose Transport Mutants for Production of Aromatic Pathway Compounds. WO patent 96/34961. 1996.

33. Meza E, Becker J, Bolivar F, Gosset G, Wittmann C: Consequences of phosphoenolpyruvate: sugar phosphotranferase system and pyruvate kinase isozymes inactivation in central carbon metabolism flux distribution in Escherichia coli. Microb Cell Fact 2012, 11:127.

34. Sabido A, Sigala JC, Hernández-Chávez G, Flores N, Gosset G, Bolívar F: Physiological and transcriptional characterization of Escherichia coli strains lacking interconversion of phosphoenolpyruvate and pyruvate when glucose and acetate are coutilized. Biotechnol Bioeng 2014 111:1150-1160

35. Patnaik R, Liao JC: Engineering of Escherichia coli central metabolism for aromatic metabolite production with near theoretical yield. Appl Environ Microbiol 1994, 60:3903-3908.

36. Liao JC: Microorganisms and Methods for Overproduction of DAHP by Cloned pps Gene. WO patent 96/08567. 1996

37. Yi J, Li K, Draths KM, Frost JW: Modulation of phosphoenolpyruvate synthase expression increases shikimate pathway product yields in E. coli. Biotechnol Prog 2002, 18:1141-1148.

38. Liao JC, Hou SY, Chao YP: Pathway analysis, engineering, and physiological considerations for redirecting central metabolism. Biotechnol Bioeng 1996, 52:129-140.

39. Gulevich AY, Biryukova IV, Zimenkov DV, Skorokhodova AY, Kivero AD, Belareva AV, Mashko SV: Method for Producing An L-amino Acid Using A Bacterium Having Enhanced Expression of the pckA Gene. US Patent 2006/0035348 A1. 2006.

40. Tatarko M, Romeo T: Disruption of a global regulatory gene to enhance central carbon flux into phenylalanine biosynthesis in Escherichia coli. Curr Microbiol 2001, 43:26-32
41. Yakandawala N, Romeo T, Friesen AD, Madhyastha S: Metabolic engineering of Escherichia coli to enhance phenylalanine production. Appl Microbiol Biotechnol 2008, 78:283-291.

42. Zhao G, Winkler ME: An Escherichia coli K-12 tktA tktB mutant deficient in transketolase activity requires pyridoxine (vitamin $B 6$ ) as well as the aromatic amino acids and vitamins for growth. J Bacterio/ 1994, 176:6134-6138.

43. Nakahigashi K, Toya Y, Ishii N, Soga T, Hasegawa M, Watanabe H, Takai Y, Honma M, Mori H, Tomita M: Systematic phenome analysis of Escherichia coli multiple-knockout mutants reveals hidden reactions in central carbon metabolism. Mol Syst Biol 2009, 5:306.

44. Draths KM, Pompliano DL, Conley DL, Frost JW, Berry A, Disbrow GL, Staversky RJ, Lievense JC: Biocatalytic synthesis of aromatics from D-Glucose: the role of transketolase. J Am Chem Soc 1992, 114:3956-3962.

45. Patnaik R, Spitzer RG, Liao JC: Pathway engineering for production of aromatics in Escherichia coli: confirmation of stoichiometric analysis by independent modulation of AroG, TktA, and Pps activities. Biotechnol Bioeng 1995, 46:361-370.

46. Báez JL, Bolívar F, Gosset G: Determination of 3-deoxy-D-arabino-heptulosonate 7-phosphate productivity and yield from glucose in Escherichia coli devoid of the glucose phosphotransferase transport system. Biotechnol Bioeng 2001, 73:530-535.

47. Lu J, Liao JC: Metabolic engineering and control analysis for production of aromatics: role of transaldolase. Biotechnol Bioeng 1997, 53:132-138.

48. Mascarenhas D, Ashworth DJ, Chen CS: Deletion of pgi alters tryptophan biosynthesis in a genetically engineered strain of Escherichia coli. Appl Environ Microbiol 1991, 57:2995-2999.

49. Ahn J, Chung BKS, Lee D, Park M, Karimi IA, Jung J, Lee H: NADPH-dependent pgi-gene knockout Escherichia coli metabolism producing shikimate on different carbon sources. FEMS Microbiol Lett 2011, 324:10-16.

50. Rodriguez A, Martínez JA, Báez-Viveros JL, Flores N, Hernández-Chávez G, Ramírez OT, Gosset G, Bolivar F: Constitutive expression of selected genes from the pentose phosphate and aromatic pathways increases the shikimic acid yield in high-glucose batch cultures of an Escherichia coli strain lacking PTS and pykF. Microb Cell Fact 2013, 12:86.

51. Li K, Frost JW: Microbial synthesis of 3-dehydroshikimic acid: a comparative analysis of D-xylose, L-arabinose, and D-glucose carbon sources. Biotechnol Prog 1999, 15:876-883.

52. Martínez K, De Anda R, Hernández G, Escalante A, Gosset G, Ramírez OT, Bolivar F: Coutilization of glucose and glycerol enhances the production of aromatic compounds in an Escherichia coli strain lacking the phosphoenolpyruvate: carbohydrate phosphotransferase system. Microb Cell Fact 2008, 7:1.

53. Ahn JO, Lee HW, Saha R, Park MS, Jung JK, Lee DY: Exploring the effects of carbon sources on the metabolic capacity for shikimic acid production in Escherichia coli using in silico metabolic predictions. J Microbiol Biotechnol 2008, 18:1773-1784.

54. Chen K, Dou J, Tang S, Yang Y, Wang H, Fang H, Zhou C: Deletion of the aroK gene is essential for high shikimic acid accumulation through the shikimate pathway in E. coli. Bioresour Technol 2012, 119:141-147.

55. Báez-Viveros JL, Osuna J, Hernández-Chávez G, Soberón X, Bolívar F, Gosset G: Metabolic engineering and protein directed evolution increase the yield of L-phenylalanine synthesized from glucose in Escherichia coli. Biotechnol Bioeng 2004, 87:516-524.

56. Liu S-P, Xiao M-R, Zhang L, Xu J, Ding Z-Y, Gu Z-H, Shi G-Y: Production of $\mathrm{L}$-phenylalanine from glucose by metabolic engineering of wild type Escherichia coli W3110. Process Biochem 2013, 48:413-419.

57. Chavez-Bejar MI, Lara AR, Lopez H, Hernandez-Chavez G, Martinez A, Ramirez OT, Bolivar F, Gosset G: Metabolic engineering of Escherichia coli for L-tyrosine production by expression of genes coding for the chorismate mutase domain of the native chorismate mutase-prephenate dehydratase and a cyclohexadienyl dehydrogenase from Zymomonas mobilis. Appl Environ Microbiol 2008, 74:3284-3290.

58. Juminaga D, Baidoo EEK, Redding-Johanson AM, Batth TS, Burd H, Mukhopadhyay A, Petzold CJ, Keasling JD: Modular engineering of L-tyrosine production in Escherichia coli. Appl Environ Microbiol 2012, 78:89-98.

59. Zhao Z-J, Zou C, Zhu Y-X, Dai J, Chen S, Wu D, Wu J, Chen J: Development of L-tryptophan production strains by defined genetic modification in Escherichia coli. J Ind Microbiol Biotechnol 2011, 38:1921-1929.

60. Shen T, Liu Q, Xie X, Xu Q, Chen N: Improved production of tryptophan in genetically engineered Escherichia coli with TktA and PpsA overexpression. J Biomed Biotechnol 2012, 2012:1-8. 
61. Wang J, Cheng L-K, Wang J, Liu Q, Shen T, Chen N: Genetic engineering of Escherichia coli to enhance production of L-tryptophan. Appl Microbiol Biotechnol 2013, 97:7587-7596.

62. Doroshenko VG, Tsyrenzhapova IS, Krylov AA, Kiseleva EM, Ermishev VY, Kazakova SM, Biryukova IV, Mashko SV: Pho regulon promoter-mediated transcription of the key pathway gene aroGFbr improves the performance of an L-phenylalanine-producing Escherichia coli strain. Appl Microbiol Biotechnol 2010, 88:1287-1295.

63. Dell KA, Frost JW: Identification and removal of impediments to biocatalytic synthesis of aromatics from D-Glucose: rate-limiting enzymes in the common pathway of aromatic amino acid biosynthesis. J Am Chem Soc 1993, 115:11581-11589.

64. Krämer M, Bongaerts J, Bovenberg R, Kremer S, Müller U, Orf S, Wubbolts M, Raeven L: Metabolic engineering for microbial production of shikimic acid. Metab Eng 2003, 5:277-283.

65. Oldiges M, Kunze M, Degenring D, Sprenger GA, Takors R: Stimulation, monitoring, and analysis of pathway dynamics by metabolic profiling in the aromatic amino acid pathway. Biotechnol Prog 2004, 20:1623-1633.

66. Escalante A, Calderón R, Valdivia A, De Anda R, Hernández G, Ramírez OT, Gosset G, Bolivar F: Metabolic engineering for the production of shikimic acid in an evolved Escherichia coli strain lacking the phosphoenolpyruvate: carbohydrate phosphotransferase system. Microb Cell Fact 2010, 9:21.

67. Lutke-Eversloh T, Stephanopoulos G: Feedback inhibition of chorismate mutase/prephenate dehydrogenase (TyrA) of Escherichia coli: Generation and characterization of tyrosine-insensitive mutants. Appl Environ Microbiol 2005, 71:7224-7228

68. Cui $Y-Y$, Ling C, Zhang $Y-Y$, Huang J, Liu J-Z: Production of shikimic acid from Escherichia coli through chemically inducible chromosomal evolution and cofactor metabolic engineering. Microb Cell Fact 2014, 13:21

69. Johansson L, Lindskog A, Silfversparre G, Cimander C, Nielsen KF, Lidén G: Shikimic acid production by a modified strain of $E$. coli (W3110.shik1) under phosphate-limited and carbon-limited conditions. Biotechnol Bioeng 2005, 92:541-552

70. Chen X, Li M, Zhou L, Shen W, Algasan G, Fan Y, Wang Z: Metabolic engineering of Escherichia coli for improving shikimate synthesis from glucose. Bioresour Technol 2014, 166:64-71.

71. Ghosh S, Chisti Y, Banerjee UC: Production of shikimic acid. Biotechnol Adv 2012, 30:1425-1431.

72. Rawat G, Tripathi P, Saxena RK: Expanding horizons of shikimic acid: Recent progresses in production and its endless frontiers in application and market trends. Appl Microbiol Biotechnol 2013, 97:4277-4287.

73. Tripathi P, Rawat G, Yadav S, Saxena RK: Fermentative production of shikimic acid: a paradigm shift of production concept from plant route to microbial route. Bioprocess Biosyst Eng 2013, 36:1665-1673.

74. Estevez A, Estevez R: A short overview on the medicinal chemistry of (-)-shikimic acid. Mini Rev Med Chem 2012, 12:1443-1454.

75. Salgado H, Peralta-Gil M, Gama-Castro S, Santos-Zavaleta A, Muñiz-Rascado L, García-Sotelo JS, Weiss V, Solano-Lira H, Martínez-Flores I, Medina-Rivera A, Salgado-Osorio G, Alquicira-Hernández S, Alquicira-Hernández K, López-Fuentes A, Porrón-Sotelo L, Huerta AM, Bonavides-Martínez C, Balderas-Martínez YI, Pannier L, Olvera M, Labastida A, Jiménez-Jacinto V, Vega-Alvarado L, Del Moral-Chávez V, Hernández-Alvarez A, Morett E, Collado-Vides J: RegulonDB v8.0: omics data sets, evolutionary conservation, regulatory phrases, cross-validated gold standards and more. Nucleic Acids Res 2013, 41(Database issue):D203-D213.

76. Báez-Viveros J, Flores N, Juárez K, Castillo-España P, Bolivar F, Gosset G: Metabolic transcription analysis of engineered Escherichia coli strains that overproduce L-phenylalanine. Microb Cell Fact 2007, 6:30.

77. Doroshenko VG, Shakulov RS, Kazakova SM, Kivero AD, Yampolskaya TA, Mashko SV: Construction of an L-phenylalanine-producing tyrosine-prototrophic Escherichia coli strain using tyrA ssrA-like tagged alleles. Biotechnol Lett 2010, 32:1117-1121.

78. Doroshenko V, Airich L, Vitushkina M, Kolokolova A, Livshits V, Mashko S. YddG from Escherichia coli promotes export of aromatic amino acids. FEMS Microbiol Lett 2007, 275:312-318.

79. Liu Q, Cheng Y, Xie X, Xu Q, Chen N: Modification of tryptophan transport system and its impact on production of L-tryptophan in Escherichia coli. Bioresour Technol 2012, 114:549-554.
80. Gu P, Yang F, Li F, Liang Q, Qi Q: Knocking out analysis of tryptophan permeases in Escherichia coli for improving L-tryptophan production. Appl Microbiol Biotechnol 2013, 97:6677-6683.

81. Gu P, Yang F, Kang J, Wang Q, Qi Q: One-step of tryptophan attenuato inactivation and promoter swapping to improve the production of L-tryptophan in Escherichia coli. Microb Cell Fact 2012, 11:30.

82. Rodrigues AL, Trachtmann N, Becker J, Lohanatha AF, Blotenberg J, Bolten CJ, Korneli C, De Souza Lima AO, Porto LM, Sprenger GA, Wittmann C: Systems metabolic engineering of Escherichia coli for production of the antitumor drugs violacein and deoxyviolacein. Metab Eng 2013, 20:29-41.

83. Koma D, Yamanaka H, Moriyoshi K, Ohmoto T, Sakai K: Production of aromatic compounds by metabolically engineered Escherichia coli with an expanded shikimate pathway. Appl Environ Microbiol 2012, 78:6203-6216.

84. Muñoz AJ, Hernández-Chávez G, Anda R, Martínez A, Bolívar F, Gosset G: Metabolic engineering of Escherichia coli for improving L-3,4-dihydroxyphenylalanine (L-DOPA) synthesis from glucose. J Ind Microbiol Biotechnol 2011, 38:1845-1852.

85. Sun Z, Ning Y, Liu L, Liu Y, Sun B, Jiang W, Yang C, Yang S: Metabolic engineering of the L-phenylalanine pathway in Escherichia coli for the production of S- or R-mandelic acid. Microb Cell Fact 2011, 10:71.

86. Rodrigues AL, Becker J, De Souza Lima AO, Porto LM, Wittmann C: Systems metabolic engineering of Escherichia coli for gram scale production of the antitumor drug deoxyviolacein from glycerol. Biotechnol Bioeng 2014, $20: 1-31$.

87. Eudes A, Juminaga D, Baidoo EE, Collins FW, Keasling JD, Loqué D: Production of hydroxycinnamoyl anthranilates from glucose in Escherichia coli. Microb Cell Fact 2013, 12:62

88. Lim CG, Fowler ZL, Hueller T, Schaffer S, Koffas MAG: High-yield resveratrol production in engineered Escherichia coli. Appl Environ Microbiol 2011, 77:3451-3460.

89. Lynch SA, Gill RT: Synthetic biology: New strategies for directing design. Metab Eng 2012, 14:205-211.

90. Luo Y, Lee J-K, Zhao H: Challenges and opportunities in synthetic biology for chemical engineers. Chem Eng Sci 2013, 103:115-119.

91. Boyle PM, Silver PA: Parts plus pipes: Synthetic biology approaches to metabolic engineering. Metab Eng 2012, 14:223-232.

92. Yadav VG, De Mey M, Giaw Lim C, Kumaran Ajikumar P, Stephanopoulos G: The future of metabolic engineering and synthetic biology: Towards a systematic practice. Metab Eng 2012, 14:233-241.

93. Lütke-Eversloh T, Stephanopoulos G: Combinatorial pathway analysis for improved L-tyrosine production in Escherichia coli: identification of enzymatic bottlenecks by systematic gene overexpression. Metab Eng 2008, 10:69-77.

94. Yao Y-F, Wang C-S, Qiao J, Zhao G-R: Metabolic engineering of Escherichia coli for production of salvianic acid A via an artificial biosynthetic pathway. Metab Eng 2013, 19:79-87.

95. Albermann C, Ghanegaonkar S, Lemuth K, Vallon T, Reuss M, Armbruster W, Sprenger $\mathrm{G}$ a: Biosynthesis of the vitamin E compound delta-tocotrienol in recombinant Escherichia coli cells. Chembiochem 2008, 9:2524-2533.

96. Ghanegaonkar S, Conrad J, Beifuss U, Sprenger G a, Albermann C: Towards the in vivo production of tocotrienol compounds: engineering of a plasmid-free Escherichia coli strain for the heterologous synthesis of 2methyl-6-geranylgeranyl-benzoquinol. J Biotechnol 2012, 164:238-247.

97. Nakagawa A, Minami H, Kim J-S, Koyanagi T, Katayama T, Sato F, Kumagai H: A bacterial platform for fermentative production of plant alkaloids. Nat Commun 2011, 2:326.

98. Wu J, Du G, Zhou J, Chen J: Metabolic engineering of Escherichia coli for (2S)-pinocembrin production from glucose by a modular metabolic strategy. Metab Eng 2013, 16:48-55.

99. Wu J, Liu P, Fan Y, Bao H, Du G, Zhou J, Chen J: Multivariate modular metabolic engineering of Escherichia coli to produce resveratrol from L-tyrosine. J Biotechnol 2013, 167:404-411.

100. Nakajima M, Nishino Y, Tamura M, Mase K, Masai E, Otsuka Y, Nakamura M, Sato K, Fukuda M, Shigehara K, Ohara S, Katayama Y, Kajita S: Microbial conversion of glucose to a novel chemical building block, 2-pyrone-4,6-dicarboxylic acid. Metab Eng 2009, 11:213-220.

101. Santos CNS, Xiao W, Stephanopoulos G: Rational, combinatorial, and genomic approaches for engineering L-tyrosine production in Escherichia coli. Proc Natl Acad Sci 2012, 109:13538-13543.

102. Alper H, Stephanopoulos G: Global transcription machinery engineering: A new approach for improving cellular phenotype. Metab Eng 2007, 9:258-267. 
103. Kang S-Y, Choi O, Lee JK, Hwang BY, Uhm T-B, Hong Y-S: Artificial biosynthesis of phenylpropanoic acids in a tyrosine overproducing Escherichia coli strain. Microb Cell Fact 2012, 11:153.

104. Zhang H, Stephanopoulos G: Engineering E. coli for caffeic acid biosynthesis from renewable sugars. Appl Microbiol Biotechnol 2013, 97:3333-3341.

105. Huang Q, Lin Y, Yan Y: Caffeic acid production enhancement by engineering a phenylalanine over-producing Escherichia coli strain. Biotechnol Bioeng 2013, 110:3188-3196.

106. Satoh Y, Tajima K, Munekata M, Keasling JD, Lee TS: Engineering of L-tyrosine oxidation in Escherichia coli and microbial production of hydroxytyrosol. Metab Eng 2012, 14:603-610.

107. Wang HH, Isaacs FJ, Carr P a, Sun ZZ, Xu G, Forest CR, Church GM: Programming cells by multiplex genome engineering and accelerated evolution. Nature 2009, 460:894-898.

108. Wang HH, Kim H, Cong L, Jeong J, Bang D, Church GM: Genome-scale promoter engineering by coselection MAGE. Nat Methods 2012, 9:591-593.

109. Yang J, Seo SW, Jang S, Shin S-I, Lim CH, Roh T-Y, Jung GY: Synthetic RNA devices to expedite the evolution of metabolite-producing microbes. Nat Commun 2013, 4:1413.

110. Na D, Yoo SM, Chung H, Park H, Park JH, Lee SY: Metabolic engineering of Escherichia coli using synthetic small regulatory RNAs. Nat Biotechnol 2013, 31:170-174.

111. Shimizu K: Toward systematic metabolic engineering based on the analysis of metabolic regulation by the integration of different levels of information. Biochem Eng J 2009, 46:235-251.

112. Bro C, Nielsen J: Impact of "ome" analyses on inverse metabolic engineering. Metab Eng 2004, 6:204-211.

113. Park JH, Lee SY, Kim TY, Kim HU: Application of systems biology for bioprocess development. Trends Biotechnol 2008, 26:404-412.

114. Park JH, Lee SY: Towards systems metabolic engineering of microorganisms for amino acid production. Curr Opin Biotechnol 2008, 19:454-460.

115. Bartek T, Blombach B, Lang S, Eikmanns BJ, Wiechert W, Oldiges M, Nöh K, Noack S: Comparative $13 \mathrm{C}$ metabolic flux analysis of pyruvate dehydrogenase complex-deficient, L-valine-producing Corynebacterium glutamicum. Appl Environ Microbiol 2011, 77:6644-6652.

116. Becker J, Zelder O, Häfner S, Schröder H, Wittmann C: From zero to hero - Design-based systems metabolic engineering of Corynebacterium glutamicum for L-lysine production. Metab Eng 2011, 13:159-168.

117. Van Ooyen J, Noack S, Bott M, Reth A, Eggeling L: Improved L-lysine production with Corynebacterium glutamicum and systemic insight into citrate synthase flux and activity. Biotechnol Bioeng 2012, 109:2070-2081.

118. Singh P, Batth TS, Juminaga D, Dahl RH, Keasling JD, Adams PD, Petzold CJ: Application of targeted proteomics to metabolically engineered Escherichia coli. Proteomics 2012, 12:1289-1299.

119. Kedar $\mathrm{P}$, Colah R, Shimizu K: Proteomic investigation on the pyk-F gene knockout Escherichia coli for aromatic amino acid production. Enzyme Microb Technol 2007, 41:455-465.

120. Polen T, Krämer M, Bongaerts J, Wubbolts M, Wendisch VF: The global gene expression response of Escherichia coli to L-phenylalanine. J Biotechnol 2005, 115:221-237.

121. Cortés-Tolalpa L, Gutiérrez-Ríos RM, Martínez LM, De Anda R, Gosset G, Bolívar F, Escalante A: Global transcriptomic analysis of an engineered Escherichia coli strain lacking the phosphoenolpyruvate: carbohydrate phosphotransferase system during shikimic acid production in rich culture medium. Microb Cell Fact 2014, 13:28.

122. Johansson $\mathrm{L}$, Lidén $\mathrm{G}$ : Transcriptome analysis of a shikimic acid producing strain of Escherichia coli W3110 grown under carbon- and phosphate-limited conditions. J Biotechnol 2006, 126:528-545.

123. Joyce AR, Reed JL, White A, Edwards R, Osterman A, Baba T, Mori H, Lesely SA, Palsson BO, Agarwalla S: Experimental and computational assessment of conditionally essential genes in Escherichia coli. J Bacteriol 2006, 188:8259-8271.

124. Xu Z, Sun X, Yu S: Genome-scale analysis to the impact of gene deletion on the metabolism of $E$. coli: constraint-based simulation approach. BMC Bioinformatics 2009, 10(Suppl 1):S62.

125. Rizk ML, Liao JC: Ensemble modeling for aromatic production in Escherichia coli. PLoS One 2009, 4:e6903.

126. Takors R: Scale-up of microbial processes: Impacts, tools and open questions. J Biotechnol 2012, 160:3-9.
127. Lara AR, Galindo E, Ramirez OT, Palomares LA: Living with heterogeneities in bioreactors. Understanding the effects of environmental gradients on cells. Mol Biotechnol 2006, 34:355-381

128. Noorman $\mathrm{H}$ : An industrial perspective on bioreactor scale-down: What we can learn from combined large-scale bioprocess and model fluid studies. Biotechnol J 2011, 6:934-943.

129. Wang J, Huang J, Shi J, Xu Q, Xie X, Chen N: Fermentation characterization of an L-tryptophan producing Escherichia coli strain with inactivated phosphotransacetylase. Ann Microbiol 2013, 63:1219-1224.

130. Khamduang M, Packdibamrung K, Chutmanop J, Chisti Y, Srinophakun P: Production of L-phenylalanine from glycerol by a recombinant Escherichia coli. J Ind Microbiol Biotechnol 2009, 36:1267-1274.

131. Weiner M, Albermann C, Gottlieb K, Sprenger GA, Weuster-Botz D: Fed-batch production of $\mathrm{L}$-phenylalanine from glycerol and ammonia with recombinant Escherichia coli. Biochem Eng J 2014, 83:62-69.

132. Liu SP, Liu RX, Xiao MR, Zhang L, Ding ZY, Gu ZH, Shi GY: A systems level engineered $E$. coli capable of efficiently producing L-phenylalanine. Process Biochem 2014, 49:751-757.

133. Hu Y, Tang T, Yang W, Zhou H: Bioconversion of phenylpyruvic acid to L-phenylalanine by mixed-gel immobilization of Escherichia coli EP8-10. Process Biochem 2009, 44:142-145.

doi:10.1186/s12934-014-0126-z

Cite this article as: Rodriguez et al.: Engineering Escherichia coli to overproduce aromatic amino acids and derived compounds. Microbial Cell Factories 2014 13:126.

\section{Submit your next manuscript to BioMed Central and take full advantage of:}

- Convenient online submission

- Thorough peer review

- No space constraints or color figure charges

- Immediate publication on acceptance

- Inclusion in PubMed, CAS, Scopus and Google Scholar

- Research which is freely available for redistribution
C Biomed Central 